\title{
Hypochondriasis as a distinct phenomenological presentation of complicated grief
}

\section{Bárbara Almeida ${ }^{1}$, Gustavo Santos ${ }^{1}$}

${ }^{1}$ Hospital Magalhães Lemos, Porto, Portugal.

Received: 11/5/2017 - Accepted: 11/22/2017

DOl: 10.1590/0101-60830000000150

Almeida B, Santos G / Arch Clin Psychiatry. 2018;45(1):25

\section{Dear Editor,}

Grief is a psychobiological response with emotional, cognitive and behavioural components ${ }^{1}$. The experience of grief in reaction to loss is universal, yet there is lack of an integrative theory of bereavement which could merge neurobiological, psychological and sociocultural factors $^{2}$. Unsurprisingly, during the last decades, grief has posed a nosological challenge, in which the border between normal and pathological reactions may not always be clear³.

Through the presentation of the following clinical vignette, we aim to attract more attention to highly heterogeneous phenomenology of grief reaction. We report a 20 -years old female, farmer, single (and lived with her parents). She had no relevant past medical and psychiatric history. She attended our outpatient department for panic disorder that started after her grandfather's death (a very important figure in her life), two years prior, in the context of a rapid progressive colon cancer. She consulted previously a psychiatrist and took escitalopram, but she abandoned after four months, without improvement. Apart from the panic attacks, she also presented feelings of acute grief - intense sadness, crying, feelings of guilt about his death, the sensation of his presence around her and vivid dreams - and hypochondriac symptoms: the belief that there was something wrong with her body and something bad could be happening with her (not related with the panic attacks) despite the normal medical exams done by her general practitioner (echocardiogram, electrocardiogram and several blood tests). She missed her work, got isolated from social contacts and visited many times her general practitioner asking for repeatedly medical examinations. Given the severity of the symptoms, we started Sertraline ( $50 \mathrm{mg} /$ day) and supportive psychotherapy. The symptoms resolved after six months. We conceptualized this clinical case as a complicated grief with secondary panic attacks and hypochondriasis. In the setting provided, patient was able to do her grief work and adapt/cope with her lost, with the subsequent resolution of the symptoms.
Hypochondriacal symptoms could be found in a wide range of mental disorders. Interestingly, hypochondriasis was seen psychodynamically as a defence against guilt or low self-esteem ${ }^{4}$, which bears obvious resemblances with the role of self-blame in bereavement ${ }^{5}$. One could say: "Why should I be healthy now that my grandfather is dead from a disease I couldn't help?".

Focusing on the phenomenological account of the patient, the misinterpretation of otherwise normal bodily sensations could be triggered or aggravated by the emotional state (due to grief) ${ }^{6}$. The overvalued ideas firmly held by the patient refer to a fear of illness, which could mediate a deeper fear of death.

We also suggest that the first trial of SSRI (escitalopram) failed, at least in part because the psychosocial aspects of grief were underlooked. Supportive psychotherapy promoted emotional repair and cognitive restructuring with new coping strategies.

As far as we know this is the first report in the literature of hypochondriasis as a phenomenological presentation of complicate grief. This article outlines the need to recognize hypochondriasis in times of distress, avoiding unnecessary exams and investigation, and prompting supportive psychotherapy, tailored to the singularity of the grief process.

\section{References}

1. Shear MK, Ghesquiere A, Glickman K. Bereavement and complicated grief. Curr Psychiatry Rep. 2013;15(11):406.

2. Rothaupt JW, Becker K. A literature review of Western bereavement theory: from decathecting to continuing bonds. Fam J. 2007;15(1):6-15.

3. Weiner SJ. The stage theory of grief. JAMA. 2007;297(24):2692-3

4. Röder CH, Overbeck G, Müller T. [Psychoanalytic theories of hypochondria]. Psyche (Stuttg). 1995;49(11):1068-98.

5. Stroebe M, Stroebe W, van de Schoot R, Schut H, Abakoumkin G, Li J. Guilt in bereavement: the role of self-blame and regret in coping with loss. PLoS One. 2014;9(5):e96606.

6. Olatunji BO, Deacon BJ, Abramowitz JS. Is hypochondriasis an anxiety disorder? Br J Psychiatry. 2009;194(6):481-2. 